\title{
On some fixed points of $\alpha-\psi$ contractive mappings with rational expressions
}

\author{
Erdal Karapınar ${ }^{a, *}$, Abdelkader Dehici ${ }^{b}$, Nadjeh Redjel $^{\mathrm{C}}$ \\ ${ }^{a}$ Nonlinear Analysis and Applied Mathematics (NAAM) Research Group, King Abdulaziz University, 21589, Jeddah, S. A. \\ ${ }^{b}$ Department of Mathematics and Informatics, University of Souk-Ahras, P. O. Box 1553, Souk-Ahras 41000, Algeria. \\ ${ }^{c}$ Department of Mathematics University of Constantine 1, Constantine 25000, Algeria.
}

Communicated by B. Samet

\begin{abstract}
In this paper, we study the existence and uniqueness of fixed points for a new class of contractive mappings involving rational expressions, which enable us to extend many known results in the literature. We consider illustrative example and consequences to underline the novelty of the main results. (C)2017 All rights reserved.
\end{abstract}

Keywords: Complete metric space, (c)-comparison function, fixed point, $\alpha$-admissible mapping, cyclic mapping. 2010 MSC: 46T99, 47H10, 54H25.

\section{Introduction and preliminaries}

Throughout the paper, let $\mathbb{N}$ represent positive integers and $\mathbb{N}_{0}=\mathbb{N} \cup\{0\}$. A mapping $\varphi:[0, \infty) \rightarrow$ $[0, \infty)$ is called a comparison function if it is increasing and $\varphi^{\mathrm{n}}(\mathrm{t}) \rightarrow 0, \mathrm{n} \rightarrow \infty$ for any $\mathrm{t} \in[0, \infty)$, where $\mathrm{n} \in \mathbb{N}$. We denote by $\Phi$, the class of the comparison functions $\varphi:[0, \infty) \rightarrow[0, \infty)$. For more details and illustrative examples, we refer, e.g., [5, 22]. Among them, we recall the following essential result.

Lemma $1.1([5,22])$. If $\varphi:[0, \infty) \rightarrow[0, \infty)$ is a comparison function, then:

(1) each iterate $\varphi^{\mathrm{k}}$ of $\varphi, k \geqslant 1$, is also a comparison function;

(2) $\varphi$ is continuous at 0 ;

(3) $\varphi(t)<t$ for any $t>0$.

Let $\Psi$ be the family of nondecreasing functions $\psi:[0, \infty) \rightarrow[0, \infty)$ so that $\sum_{n=1}^{\infty} \psi^{n}(t)<\infty$ for each $\mathrm{t}>0$, where $\psi^{\mathrm{n}}$ is the $\mathrm{n}$-th iterate of $\psi$. It is clear that $\Phi \subset \Psi$ (see, e.g., [13]) and hence, by Lemma 1.1 (3), for $\psi \in \Psi$ we have $\psi(t)<t$ for any $t>0$.

Recently, Samet et al. [24] introduced the following concept.

\footnotetext{
${ }^{*}$ Corresponding author

Email addresses: erdalkarapinar@yahoo.com (Erdal Karapınar), dehicikader@yahoo.fr (Abdelkader Dehici), najehredjel@yahoo.fr (Nadjeh Redjel)

doi:10.22436/jnsa.010.04.23
} 
Definition 1.2. Let $(X, d)$ be a metric space, $f: X \longrightarrow X$ be a given mapping and $\alpha: X \times X \longrightarrow[0, \infty)$. We say that $f$ is $\alpha$-admissible if for all $x, y \in X$, we have

$$
\alpha(x, y) \geqslant 1 \Longrightarrow \alpha(f(x), f(y)) \geqslant 1 \text {. }
$$

Example 1.3. For $X=\mathbb{R}$ we define $f: X \longrightarrow X$ and $\alpha: X \times X \longrightarrow[0, \infty)$ by $f(x)=\frac{x}{3}$ and

$$
\alpha(x, y)= \begin{cases}3, & \text { if } x \geqslant y \\ 0, & \text { otherwise }\end{cases}
$$

respectively. Then $f$ is $\alpha$-admissible.

For some other examples concerning the class of $\alpha$-admissible mappings, we can see $[2,3,7,9,19,24]$.

Definition 1.4. Let $(X, d)$ be a metric space and $f: X \rightarrow X$ be a given mapping. We say that $f$ is $\alpha-\psi$-contractive mapping if there exist two functions $\alpha: X \times X \longrightarrow[0, \infty)$ and $\psi \in \Psi$ such that

$$
\alpha(x, y) d(f(x), f(y)) \leqslant \psi(d(x, y)) .
$$

The main results in [24] are the following fixed point theorems.

Theorem 1.5. Let $(X, d)$ be a complete metric space and $\mathrm{f}: \mathrm{X} \longrightarrow \mathrm{X}$ be an $\alpha-\psi$-contractive mapping. Suppose that

(i) $\mathrm{f}$ is $\alpha$-admissible;

(ii) there exists $x_{0} \in X$ such that $\alpha\left(x_{0}, f\left(x_{0}\right)\right) \geqslant 1$;

(iii) $f$ is continuous.

Then there exists $u \in X$ such that $\mathrm{f}(\mathrm{u})=\mathrm{u}$.

We denote by Fix $(f)$ the set of fixed points of $f$. For the uniqueness, we need the following additional condition.

(H) For all $x, y \in \operatorname{Fix}(f)$, there exists $z \in X$ such that $\alpha(z, x) \geqslant 1$ and $\alpha(z, y) \geqslant 1$.

Theorem 1.6. Adding to the hypotheses of Theorem 1.5 the condition $(\mathrm{H})$, one obtains the uniqueness of the fixed point.

In this paper, we propose a new notion, $\alpha-\psi$-contractive type mappings using rational expressions. We investigate the existence and uniqueness of fixed points for such mappings that enable us to extend many known results in the literature. More precisely, our main result unifies the fixed point results in the setting of partially ordered metric spaces, in the context of cyclic mappings, besides the standard metric space, by choosing the auxiliary function $\alpha(x, y)$. Additionally, we consider an example and an application to illustrate the main results.

\section{Main results}

We start this section by introducing the concept of $\alpha-\psi-K-$ mappings.

Definition 2.1. Let $(X, d)$ be a metric space and $f: X \longrightarrow X$ be a given mapping. We say that $f$ is $\alpha-\psi-K-$ mapping if there exist two functions $\alpha: X \times X \longrightarrow[0, \infty)$ and $\psi \in \Psi$ such that for all $x, y \in X, x \neq y$, we have

$$
\alpha(x, y) d(f(x), f(y)) \leqslant \psi(K(x, y))
$$

where

$$
\begin{gathered}
K(x, y)=\max \left\{d(x, y), \frac{d(x, f(x))+d(y, f(y))}{2}, \frac{d(x, f(y))+d(y, f(x))}{2},\right. \\
\left.\frac{d(x, f(x)) d(y, f(y))}{d(x, y)}, \frac{d(y, f(y))[1+d(x, f(x))]}{[1+d(x, y)]}\right\} .
\end{gathered}
$$


Remark 2.2. Every $\alpha-\psi$-contractive mapping is $\alpha-\psi-\mathrm{K}$-mapping.

Theorem 2.3. Let $(X, d)$ be a complete metric space. Suppose that $\mathrm{f}: \mathrm{X} \longrightarrow \mathrm{X}$ is $\alpha-\psi-\mathrm{K}$-mapping satisfying the following conditions:

(i) $f$ is $\alpha$-admissible;

(ii) there exists $x_{0} \in X$ such that $\alpha\left(x_{0}, f\left(x_{0}\right)\right) \geqslant 1$;

(iii) $f$ is continuous.

Then there exists $\mathrm{u} \in \mathrm{X}$ such that $\mathrm{f}(\mathrm{u})=\mathrm{u}$.

Proof. From condition (ii) there exists $x_{0} \in X$ such that $\alpha\left(x_{0}, f\left(x_{0}\right)\right) \geqslant 1$. Define the sequence $\left\{x_{n}\right\}$ in $X$ by $x_{n+1}=f\left(x_{n}\right)=f x_{n}$ for all $n \in \mathbb{N}_{0}$. If $x_{n_{0}}=x_{n_{0}+1}$ for some $n_{0} \in \mathbb{N}_{0}$, then $u=x_{n_{0}}$ is a fixed point of $f$. Assume that $x_{n} \neq x_{n+1}$ for all $n \in \mathbb{N}_{0}$. By condition (i), we derive that

$$
\alpha\left(x_{0}, x_{1}\right)=\alpha\left(x_{0}, f\left(x_{0}\right)\right) \geqslant 1 \Longrightarrow \alpha\left(f\left(x_{0}\right), f\left(x_{1}\right)\right)=\alpha\left(x_{1}, x_{2}\right) \geqslant 1 .
$$

By induction, we get

$$
\alpha\left(x_{n}, x_{n+1}\right) \geqslant 1, \quad \forall n \in \mathbb{N}_{0} .
$$

From (2.1) and (2.2), we infer that for all $n \in \mathbb{N}_{0}$,

$$
d\left(x_{n+1}, x_{n+2}\right)=d\left(f\left(x_{n}\right), f\left(x_{n+1}\right)\right) \leqslant \alpha\left(x_{n}, x_{n+1}\right) d\left(f\left(x_{n}\right), f\left(x_{n+1}\right)\right) \leqslant \psi\left(K\left(x_{n}, x_{n+1}\right)\right) .
$$

On the other hand, we have

$$
\begin{aligned}
& K\left(x_{n}, x_{n+1}\right)=\max \left\{d\left(x_{n}, x_{n+1}\right), \frac{d\left(x_{n}, f\left(x_{n}\right)\right)+d\left(x_{n+1}, f\left(x_{n+1}\right)\right)}{2},\right. \\
& \frac{d\left(x_{n}, f\left(x_{n+1}\right)\right)+d\left(x_{n+1}, f\left(x_{n}\right)\right)}{2}, \frac{d\left(x_{n}, f\left(x_{n}\right)\right) d\left(x_{n+1}, f\left(x_{n+1}\right)\right)}{d\left(x_{n}, x_{n+1}\right)}, \\
& \left.\frac{d\left(x_{n}, f\left(x_{n}\right)\right)\left[1+d\left(x_{n+1}, f\left(x_{n+1}\right)\right)\right]}{\left[1+d\left(x_{n}, x_{n+1}\right)\right]}\right\} \\
& =\max \left\{d\left(x_{n}, x_{n+1}\right), \frac{d\left(x_{n}, x_{n+1}\right)+d\left(x_{n+1}, x_{n+2}\right)}{2}, \frac{d\left(x_{n}, x_{n+2}\right)+d\left(x_{n+1}, x_{n+1}\right)}{2},\right. \\
& \left.\frac{d\left(x_{n}, x_{n+1}\right) d\left(x_{n+1}, x_{n+2}\right)}{d\left(x_{n}, x_{n+1}\right)}, \frac{d\left(x_{n}, x_{n+1}\right)\left[1+d\left(x_{n}, x_{n+1}\right)\right]}{\left[1+d\left(x_{n}, x_{n+1}\right)\right]}\right\} \\
& =\max \left\{d\left(x_{n}, x_{n+1}\right), \frac{d\left(x_{n}, x_{n+1}\right)+d\left(x_{n+1}, x_{n+2}\right)}{2}, \frac{d\left(x_{n}, x_{n+2}\right)}{2}, d\left(x_{n}, x_{n+1}\right)\right\} \\
& =\max \left\{d\left(x_{n}, x_{n+1}\right), \frac{d\left(x_{n}, x_{n+1}\right)+d\left(x_{n+1}, x_{n+2}\right)}{2}, d\left(x_{n}, x_{n+1}\right)\right\} \\
& =\max \left\{d\left(x_{n}, x_{n+1}\right), d\left(x_{n+1}, x_{n+2}\right)\right\} \text {. }
\end{aligned}
$$

Thus (2.3) and (2.4) together with the fact that $\psi$ is nondecreasing give that

$$
\left.d\left(x_{n}, x_{n+1}\right)\right) \leqslant \psi\left(\max \left\{d\left(x_{n}, x_{n+1}\right), d\left(x_{n}, x_{n+1}\right)\right\}\right) .
$$

If for some $n \in \mathbb{N}_{0}$, we have $d\left(x_{n}, x_{n+1}\right) \leqslant d\left(x_{n+1}, x_{n+2}\right)$, from (2.5), we obtain that

$$
d\left(x_{n+1}, x_{n+2}\right) \leqslant \psi\left(d\left(x_{n+1}, x_{n+2}\right)\right)<d\left(x_{n+1}, x_{n+2}\right),
$$

which is a contradiction. Thus, for all $n \in \mathbb{N}_{0}$, we have

$$
\max \left\{\left(d\left(x_{n}, x_{n+1}\right), d\left(x_{n+1}, x_{n+2}\right)\right\}=d\left(x_{n}, x_{n+1}\right) .\right.
$$


Using (2.5) and (2.6), we get that

$$
d\left(x_{n+1}, x_{n+2}\right) \leqslant \psi\left(d\left(x_{n}, x_{n+1}\right)\right) .
$$

By induction, we obtain that for all $n \in \mathbb{N}_{0}$,

$$
d\left(x_{n}, x_{n+1}\right) \leqslant \psi^{n}\left(d\left(x_{0}, x_{1}\right)\right) .
$$

Using the triangular inequality, for all $k \geqslant 1$, it follows that

$$
\begin{aligned}
d\left(x_{n}, x_{n+k}\right) & \leqslant d\left(x_{n}, x_{n+1}\right)+\cdots+d\left(x_{n+k-1}, x_{n+k}\right) \\
& \leqslant \sum_{p=n}^{n+k-1} \psi^{p} d\left(x_{0}, x_{1}\right) \\
& \leqslant \sum_{p=n}^{+\infty} \psi^{p}\left(d\left(x_{0}, x_{1}\right)\right) \longrightarrow 0 \text { as } n \longrightarrow \infty
\end{aligned}
$$

This shows that $\left\{x_{n}\right\}$ is a Cauchy sequence in $(X, d)$. Since $(X, d)$ is complete, there exists $u \in X$ such that

$$
\lim _{n \longrightarrow+\infty} d\left(x_{n}, u\right)=0 .
$$

On the other hand, since $f$ is continuous, then

$$
\lim _{n \rightarrow+\infty} d\left(x_{n+1}, f(u)\right)=\lim _{n \longrightarrow+\infty} d\left(f\left(x_{n}\right), f(u)\right)=0 .
$$

From (2.7) and (2.8) and the uniqueness of the limit, we deduce that $u$ is a fixed point of $f$, that is, $f(u)=u$.

In what follows we state an illustrative example.

Example 2.4. Let $X=\mathbb{R}$ be equipped with the usual metric $d(x, y)=|x-y|$ for all $x, y \in \mathbb{R}$. We consider the continuous mapping $f: X \longrightarrow X$ defined by

$$
f(x)= \begin{cases}2 x-\frac{3}{2}, & \text { if } x>1 \\ \frac{x}{2}, & \text { if } 0 \leqslant x \leqslant 1 \\ 0, & \text { if } x<0\end{cases}
$$

If we define the function $\alpha: X \times X \longrightarrow[0,+\infty[$ by

$$
\alpha(x, y)= \begin{cases}1, & \text { if } x, y \in[0,1] \\ 0, & \text { otherwise }\end{cases}
$$

we observe that $f$ is a $\alpha-\psi-K$-mapping with $\psi(t)=\frac{t}{2}$ for all $t \geqslant 0$. Indeed, we have

$$
\alpha(x, y) d(f(x), f(y)) \leqslant \frac{1}{2} d(x, y) \leqslant \psi(K(x, y)), \forall x, y \in X, x \neq y
$$

On the other hand, for $x_{0}=1$, we have $\alpha\left(x_{0}, f\left(x_{0}\right)\right)=\alpha(1, f(1))=\alpha\left(1, \frac{1}{2}\right)=1$.

The fact that $f$ is $\alpha$-admissible is trivial. So, all the hypotheses of Theorem 2.3 are satisfied. Thus $f$ has a fixed point.

Remark 2.5. Note that Theorem 2.3 does not guarantee the uniqueness of the fixed point, indeed in the above example $f$ has two fixed points $u_{1}=0$ and $u_{2}=\frac{3}{2}$. 
Theorem 2.6. Adding the condition $(\mathrm{H})$ to the hypotheses of Theorem 2.3, one obtains that $\mathrm{u}$ is the unique fixed point of $f$.

Proof. Suppose that $v$ is another fixed point of f. From $(\mathrm{H})$, there exists $z \in X$ such that

$$
\alpha(z, u) \geqslant 1, \quad \alpha(z, v) \geqslant 1 .
$$

Since $\mathrm{f}$ is $\alpha$-admissible, from (2.9), we have

$$
\alpha\left(f^{n}(z), u\right) \geqslant 1, \quad \alpha\left(f^{n}(z), v\right) \geqslant 1, \quad \forall n \geqslant 0 .
$$

Define the sequence $\left\{z_{n}\right\}$ in $X$ by $z_{n+1}=f\left(z_{n}\right)$ for all $n \geqslant 0$ and $z_{0}=z$ and assume that $d\left(z_{n}, u\right)>0$. From (2.10), for all $n$, we get

$$
d\left(z_{n+1}, u\right)=d\left(f\left(z_{n}\right), f(u)\right) \leqslant \alpha\left(z_{n}, u\right) d\left(f\left(z_{n}\right), f(u)\right) \leqslant \psi\left(K\left(z_{n}, u\right)\right) .
$$

On the other hand, we infer that

$$
\begin{aligned}
\mathrm{K}\left(z_{n}, u\right) & =\max \left\{d\left(z_{n}, u\right), \frac{d\left(z_{n}, z_{n+1}\right)}{2}, \frac{d\left(z_{n}, u\right)+d\left(u, z_{n+1}\right)}{2}\right\} \\
& =\max \left\{d\left(z_{n}, u\right), \frac{d\left(z_{n}, u\right)+d\left(u, z_{n+1}\right)}{2}\right\} \\
& \leqslant \max \left\{d\left(z_{n}, u\right), d\left(u, z_{n+1}\right)\right\} .
\end{aligned}
$$

Using (2.11) and the fact that $\psi$ is nondecreasing, we infer that

$$
d\left(z_{n+1}, u\right) \leqslant \psi\left(\max \left\{d\left(z_{n}, u\right), d\left(z_{n+1}, u\right)\right\}\right)
$$

for all $n$. If $\max \left\{d\left(z_{n}, u\right), d\left(z_{n+1}, u\right)\right\}=d\left(z_{n+1}, u\right)$, from (2.12), we obtain that

$$
d\left(z_{n+1}, u\right) \leqslant \psi\left(d\left(z_{n+1}, u\right)\right)<d\left(z_{n+1}, u\right),
$$

which is a contradiction. Thus we have $\max \left\{d\left(z_{n}, u\right), d\left(z_{n+1}, u\right)\right\}=d\left(z_{n}, u\right)$, and

$$
d\left(z_{n+1}, u\right) \leqslant \psi\left(d\left(z_{n}, u\right)\right)
$$

for all $n$. This implies that

$$
\mathrm{d}\left(z_{\mathrm{n}}, \mathrm{u}\right) \leqslant \psi^{\mathrm{n}}\left(\mathrm{d}\left(z_{0}, \mathrm{u}\right)\right), \quad \forall \mathrm{n} \geqslant 0 .
$$

Letting $n \longrightarrow \infty$ in the above inequality, we conclude that

$$
\lim _{n \rightarrow \infty} d\left(z_{n}, u\right)=0 .
$$

Similarly, one can show that

$$
\lim _{n \rightarrow \infty} d\left(z_{n}, v\right)=0 .
$$

From (2.13) and (2.14), we deduce that $u=v$. This shows that $u$ is the unique fixed point of $f$.

In the sequel, we need the following definition.

Definition 2.7. Let $(X, d)$ be a metric space and $f: X \rightarrow X$ be a given mapping. We say that $f$ is $\alpha-\psi$ $\mathrm{K}^{\star}$-mapping if there exist two functions $\alpha: X \times X \rightarrow[0, \infty)$ and $\psi \in \Psi$ such that for all $x, y \in X$, we have

$$
\alpha(x, y) d(f(x), f(y)) \leqslant \psi\left(K^{\star}(x, y)\right)
$$

where

$$
K^{\star}(x, y)=\max \left\{d(x, y), \frac{d(x, f(x))+d(y, f(y))}{2}, \frac{d(x, f(y))+d(y, f(x))}{2}, \frac{d(y, f(y))[1+d(x, f(x))]}{2[1+d(x, y)]}\right\} .
$$


In the next theorem, we will establish a fixed point result for $\alpha-\psi-K^{\star}$-mappings without the hypothesis of continuity.

Theorem 2.8. Let $(\mathrm{X}, \mathrm{d})$ be a complete metric space. Suppose that $\mathrm{f}: \mathrm{X} \longrightarrow \mathrm{X}$ is $\alpha-\psi-\mathrm{K}^{\star}$-mapping satisfying the following conditions:

(i) $\mathrm{f}$ is $\alpha$ admissible;

(ii) there exists $x_{0} \in X$ such that $\alpha\left(x_{0}, f\left(x_{0}\right)\right) \geqslant 1$;

(iii) If $\left\{x_{n}\right\}$ is a sequence in $X$ such that $\alpha\left(x_{n-1}, x_{n}\right) \geqslant 1$ for all $n$ and $x_{n} \longrightarrow x \in X$ as $n \longrightarrow \infty$, then there exists a subsequence $\left\{x_{n(k)}\right\}$ such that $\alpha\left(x_{n(k)}, x\right) \geqslant 1$ for all $k$.

Then there exists $u \in X$ such that $\mathrm{f}(\mathrm{u})=\mathrm{u}$.

Proof. Following the proof of Theorem 2.3, we know that the sequence $\left\{x_{n}\right\}$ defined by $x_{n+1}=f\left(x_{n}\right)$ for all $n \geqslant 0$, converges for some $u \in X$. Arguing as in (2.2) and using condition (iii), we obtain the existence of a subsequence $\left\{x_{n(k)}\right\}$ of $\left\{x_{n}\right\}$ such that $\alpha\left(x_{n(k)}, u\right) \geqslant 1$ for all $k$. Thus,

$$
d\left(x_{n(k)+1}, f(u)\right)=d\left(f\left(x_{n(k)}\right), f(u)\right) \leqslant \alpha\left(x_{n(k)}, u\right) d\left(f\left(x_{n(k)}\right), f(u)\right) \leqslant \psi\left(K^{\star}\left(x_{n(k)}, u\right)\right) .
$$

On the other hand, we have

$$
\begin{aligned}
& K^{\star}\left(x_{n(k)}, u\right)=\max \left\{d\left(x_{n(k)}, u\right)\right. \frac{d\left(x_{n(k)}, x_{n(k)+1}\right)+d(u, f(u))}{2}, \frac{d\left(x_{n(k)}, f(u)\right)+d\left(u, x_{n(k)+1}\right)}{2}, \\
&\left.\frac{d(u, f(u))\left(1+d\left(x_{n(k)}, x_{n(k)+1}\right)\right)}{2\left[1+d\left(x_{n(k)}, u\right)\right]}\right\} .
\end{aligned}
$$

Letting $k \longrightarrow \infty$ in the above inequality, we obtain that

$$
\lim _{n \rightarrow \infty} K^{\star}\left(x_{n(k)}, u\right)=\frac{d(u, f(u))}{2} .
$$

Suppose that $d(u, f(u))>0$. From (2.16), for $k$ large enough, we have $K^{\star}\left(x_{n(k)}, u\right)>0$, which implies that $\psi\left(K^{\star}\left(x_{n(k)}, u\right)\right)<K^{\star}\left(x_{n(k)}, u\right)$. Thus, from (2.15), we get that

$$
d\left(x_{n(k)+1}, f(u)\right)<K^{\star}\left(x_{n(k)}, u\right) .
$$

Letting $k \longrightarrow+\infty$ in the above inequality and using (2.16), we obtain that

$$
d(u, f(u)) \leqslant \frac{d(u, f(u))}{2}
$$

which is a contradiction. Thus we have necessarily $d(u, f(u))=0$, that is, $u=f(u)$.

Theorem 2.9. Adding condition $(\mathrm{H})$ to the hypotheses of Theorem 2.8, one obtains that $\mathrm{u}$ is the unique fixed point of $\mathrm{f}$.

Proof. Following the lines in the proof of Theorem 2.6, one can easily derive the desired results. We skip the details to avoid repetition.

\section{Immediate consequences}

Before listing the consequences of our main result, we mention the recent trend in fixed point theory. In the last decades, the analogs of Banach contraction mapping principle were observed in various different abstract spaces and setting, like in partially ordered set endowed with metric, and cyclic mapping. In this section, we shall show that we unify these trends by using auxiliary function $\alpha(x, y)$. As we shall 
show below, by choosing $\alpha(x, y)$ in a suitable way, we get the same fixed point results in various aspects (in the context of metric space, in the frame of partially ordered metric space and in the setting of cyclic mapping).

In this section, by taking $\alpha(x, y)=1$ in Theorem 2.6, we can obtain many known fixed point theorems as particular cases of our general framework.

We have as first result in this direction the following corollary.

Corollary 3.1. Let $(\mathrm{X}, \mathrm{d})$ be a complete metric space and $\mathrm{f}: \mathrm{X} \longrightarrow \mathrm{X}$ be a given continuous mapping. Assume that there exists $\psi \in \Psi$ such that

$$
d(f(x), f(y)) \leqslant \psi(K(x, y)), \forall(x, y) \in X \times X, x \neq y .
$$

Then $\mathrm{f}$ has a unique fixed point.

Corollary 3.2 (see Banach's contraction principle [4]). Let $(\mathrm{X}, \mathrm{d})$ be a complete metric space and $\mathrm{f}: \mathrm{X} \longrightarrow \mathrm{X}$ be a given mapping. Assume that there exists $\lambda \in(0,1)$ such that for all $x, y \in X$, we have

$$
d(f(x), f(y)) \leqslant \lambda d(x, y) .
$$

Then $\mathrm{f}$ has a unique fixed point.

Corollary $3.3([6])$. Let $(\mathrm{X}, \mathrm{d})$ be a complete metric space and $\mathrm{f}: \mathrm{X} \longrightarrow \mathrm{X}$ be a given mapping. Assume that there exists $\psi \in \Psi$ such that

$$
d(f(x), f(y)) \leqslant \psi(d(x, y)), \quad \forall(x, y) \in X \times X .
$$

Then $\mathrm{f}$ has a unique fixed point.

Corollary $3.4([14])$. Let $(\mathrm{X}, \mathrm{d})$ be a complete metric space and $\mathrm{f}: \mathrm{X} \longrightarrow \mathrm{X}$ be a given continuous mapping. Assume that there exists $\lambda_{1}, \lambda_{2} \in(0,1)$ with $\lambda_{1}+\lambda_{2}<1$ such that for all $\mathrm{x}, \mathrm{y} \in \mathrm{X}, \mathrm{x} \neq \mathrm{y}$, we have

$$
d(f(x), f(y)) \leqslant \lambda_{1} d(x, y)+\lambda_{2} \frac{d(y, f(y)) d(x, f(x))}{d(x, y)} .
$$

Then $\mathrm{f}$ has a unique fixed point.

Corollary 3.5 ([11]). Let $(\mathrm{X}, \mathrm{d})$ be a complete metric space and $\mathrm{f}: \mathrm{X} \longrightarrow \mathrm{X}$ be a given continuous mapping. Assume that there exists $\lambda \in\left(0, \frac{1}{3}\right)$ such that for all $x, y \in X, x \neq y$, we have

$$
d(f(x), f(y)) \leqslant \lambda\left(d(x, y)+\frac{d(y, f(y)) d(x, f(x))}{d(x, y)}+\frac{d(y, f(y))(1+d(x, f(x))}{1+d(x, y)}\right) .
$$

Then $\mathrm{f}$ has a unique fixed point.

Corollary 3.6. Let $(\mathrm{X}, \mathrm{d})$ be a complete metric space and $\mathrm{f}: \mathrm{X} \longrightarrow \mathrm{X}$ be a given continuous mapping. Assume that there exist constants $A, B, C, D, E \geqslant 0$ with $A+2 B+2 C+D+E \in(0,1)$ such that

$$
\begin{aligned}
d(f(x), f(y)) \leqslant & A d(x, y)+B[d(x, f(x))+d(y, f(y))]+C[d(x, f(y))+d(y, f(x))] \\
& +D \frac{d(x, f(x)) d(y, f(y))}{d(x, y)}+E \frac{d(y, f(y))[1+d(x, f(x))]}{1+d(x, y)}
\end{aligned}
$$

for all $(x, y) \in X \times X, x \neq y$. Then $\mathrm{f}$ has a unique fixed point.

By taking $\alpha(x, y)=1$ in Theorem 2.9, the following fixed point result can be deduced immediately.

Corollary 3.7. Let $(\mathrm{X}, \mathrm{d})$ be a complete metric space and $\mathrm{f}: \mathrm{X} \longrightarrow \mathrm{X}$ be a given mapping. Assume that there exists $\psi \in \Psi$ such that

$$
d(f(x), f(y)) \leqslant \psi\left(K^{\star}(x, y)\right), \quad \forall(x, y) \in X \times X .
$$

Then $\mathrm{f}$ has a unique fixed point. 
The following fixed point theorems are immediate consequences of Corollary 3.7.

Corollary 3.8 ([19]). Let $(\mathrm{X}, \mathrm{d})$ be a complete metric space and $\mathrm{f}: \mathrm{X} \longrightarrow \mathrm{X}$ be a given mapping. Assume that there exists $\psi \in \Psi$ such that

$$
d(f(x), f(y)) \leqslant \psi(M(x, y)), \forall(x, y) \in X \times X,
$$

where

$$
M(x, y)=\max \left\{d(x, y), \frac{d(x, f(x))+d(y, f(y))}{2}, \frac{d(x, f(y))+d(y, f(x))}{2}\right\}
$$

Then $\mathrm{f}$ has a unique fixed point.

Corollary 3.9 ([19]). Let $(X, d)$ be a complete metric space and $\mathrm{f}: \mathrm{X} \longrightarrow \mathrm{X}$ be a given mapping. Suppose that there exists $\lambda \in] 0,1[$ such that

$$
d(f(x), f(y)) \leqslant \lambda \max \left\{d(x, y), \frac{d(x, f(x))+d(y, f(y))}{2}, \frac{d(x, f(y))+d(y, f(x))}{2}\right\}
$$

for all $(x, y) \in X$. Then $\mathrm{f}$ has a unique fixed point.

Corollary $3.10([12])$. Let $(\mathrm{X}, \mathrm{d})$ be a complete metric space and $\mathrm{f}: \mathrm{X} \longrightarrow \mathrm{X}$ be a given mapping. Assume that there exist constants $A, B, C \geqslant 0$ with $A+2 B+2 C \in(0,1)$ such that

$$
d(f(x), f(y)) \leqslant A d(x, y)+B[d(x, f(x))+d(y, f(y))]+C[d(x, f(y))+d(y, f(x))]
$$

for all $(x, y) \in X \times X$. Then $\mathrm{f}$ has a unique fixed point.

Corollary 3.11 ([15]). Let $(\mathrm{X}, \mathrm{d})$ be a complete metric space and $\mathrm{f}: \mathrm{X} \longrightarrow \mathrm{X}$ be a given mapping. Assume that there exists $\lambda \in\left(0, \frac{1}{2}\right)$ such that for all $x, y \in X$, we have

$$
d(f(x), f(y)) \leqslant \lambda[d(x, f(x))+d(y, f(y))]
$$

Then $\mathrm{f}$ has a unique fixed point.

Corollary 3.12 ([8]). Let $(\mathrm{X}, \mathrm{d})$ be a complete metric space and $\mathrm{f}: \mathrm{X} \longrightarrow \mathrm{X}$ be a given mapping. Assume that there exists $\lambda \in\left(0, \frac{1}{2}\right)$ such that for all $x, y \in X$, we have

$$
d(f(x), f(y)) \leqslant \lambda[d(x, f(y))+d(y, f(x))] .
$$

Then $\mathrm{f}$ has a unique fixed point.

Corollary 3.13 ([10]). Let $(\mathrm{X}, \mathrm{d})$ be a complete metric space and $\mathrm{f}: \mathrm{X} \longrightarrow \mathrm{X}$ be a given mapping. Assume that there exists $\lambda \in\left(0, \frac{1}{2}\right)$ such that for all $x, y \in X$, we have

$$
d(f(x), f(y)) \leqslant \lambda\left(d(x, y)+\frac{d(y, f(y))(1+d(x, f(x))}{1+d(x, y)}\right) .
$$

Then $\mathrm{f}$ has a unique fixed point.

\section{Some reamers for cyclic contractive mappings}

Let $\left\{A_{i}: i \in \mathbb{N}\right\}$ be nonempty closed subsets of a complete metric space $(X, d)$ and $f$ be a self-mapping on $\bigcup_{i=1}^{p} A_{i}$, where $p \geqslant 2$. The paper of Kirk et al. [20] which deals with the existence and uniqueness of the mappings, $f: A_{i} \rightarrow A_{i+1}, i=1,2, \ldots, p,\left(A_{p+1}=A_{1}\right)$, called cyclic mappings, was a pioneer work. In this 
paper it was asserted that the authors extended Banach contraction principle by omitting the necessity of the mappings. Following the ideas in that paper [20], a number papers have been appeared to investigate the existence and uniqueness of cyclic mappings, see e.g. [1, 16-18, 23]. In this section, we shall illustrate that several fixed point results in the setting of cyclic mappings can be listed as consequences of Theorem 2.9 .

Before listing the consequences of our results in the framework of "cyclic mapping", we mention that the fixed point of a self-mapping $f$, with respect to the construction above, should lie in the intersection of $\bigcup_{i=1}^{p} A_{i}$. In other words, the contractive conditions for cyclic mappings necessarily imply that the intersection of $\left\{A_{i}: i \in \mathbb{N}\right\}$, more precisely, $\bigcap_{i=1}^{p} A_{i}$, is non-empty.

Now, we shall list some consequences of our main results.

Corollary 4.1. Let $\left\{\mathrm{A}_{i}\right\}_{i=1}^{2}$ be nonempty closed subsets of a complete metric space $(\mathrm{X}, \mathrm{d})$ and $\mathrm{f}: \mathrm{Y} \longrightarrow \mathrm{Y}$ be a given mapping, where $Y=A_{1} \cup A_{2}$. Suppose that the following conditions hold

(i) $f\left(A_{1}\right) \subseteq A_{2}$ and $f\left(A_{2}\right) \subseteq A_{1}$;

(ii) there exists a function $\psi \in \Psi$ such that

$$
d(f(x), f(y)) \leqslant \psi\left(K^{\star}(x, y)\right), \quad \forall(x, y) \in A_{1} \times A_{2} .
$$

Then $\mathrm{f}$ has a unique fixed point that belongs to $A_{1} \cap A_{2}$.

Proof. The proof can be obtained by the same techniques given in the proof of Corollary 3.18 in [19].

As consequences of Corollary 4.1, we have the following fixed point results.

Corollary 4.2 ([19]). Let $\left\{A_{i}\right\}_{i=1}^{2}$ be nonempty closed subsets of a complete metric space $(\mathrm{X}, \mathrm{d})$ and $\mathrm{f}: \mathrm{Y} \longrightarrow \mathrm{Y}$ be a given mapping, where $Y=A_{1} \cup A_{2}$. Suppose that the following conditions hold

(i) $f\left(A_{1}\right) \subseteq A_{2}$ and $f\left(A_{2}\right) \subseteq A_{1}$;

(ii) there exists a function $\psi \in \Psi$ such that

$$
d(f(x), f(y)) \leqslant \psi(M(x, y)), \forall(x, y) \in A_{1} \times A_{2},
$$

where

$$
M(x, y)=\max \left\{d(x, y), \frac{d(x, f(x))+d(y, f(y))}{2}, \frac{d(x, f(y))+d(y, f(x))}{2}\right\}
$$

Then $f$ has a unique fixed point that belongs to $A_{1} \cap A_{2}$.

Corollary 4.3 ([21]). Let $\left\{A_{i}\right\}_{i=1}^{2}$ be nonempty closed subsets of a complete metric space $(\mathrm{X}, \mathrm{d})$ and $\mathrm{f}: \mathrm{Y} \longrightarrow \mathrm{Y}$ be a given mapping, where $Y=A_{1} \cup A_{2}$. Suppose that the following conditions hold

(i) $f\left(A_{1}\right) \subseteq A_{2}$ and $f\left(A_{2}\right) \subseteq A_{1}$;

(ii) there exists a function $\psi \in \Psi$ such that

$$
d(f(x), f(y)) \leqslant \psi(d(x, y)), \forall(x, y) \in A_{1} \times A_{2} .
$$

Then $\mathrm{f}$ has a unique fixed point that belongs to $A_{1} \cap A_{2}$.

Corollary 4.4 ([20]). Let $\left\{A_{i}\right\}_{i=1}^{2}$ be nonempty closed subsets of a complete metric space $(\mathrm{X}, \mathrm{d})$ and $\mathrm{f}: \mathrm{Y} \longrightarrow \mathrm{Y}$ be a given mapping, where $Y=A_{1} \cup A_{2}$. Suppose that the following conditions hold

(i) $f\left(A_{1}\right) \subseteq A_{2}$ and $f\left(A_{2}\right) \subseteq A_{1}$; 
(ii) there exists a constant $\lambda \in(0,1)$ such that

$$
d(f(x), f(y)) \leqslant \lambda d(x, y), \quad \forall(x, y) \in A_{1} \times A_{2} .
$$

Then $\mathrm{f}$ has a unique fixed point that belongs to $A_{1} \cap A_{2}$.

Corollary 4.5. Let $\left\{\mathrm{A}_{i}\right\}_{i=1}^{2}$ be nonempty closed subsets of a complete metric space $(\mathrm{X}, \mathrm{d})$ and $\mathrm{f}: \mathrm{Y} \longrightarrow \mathrm{Y}$ be a given mapping, where $Y=A_{1} \cup A_{2}$. Assume that the following conditions hold

(i) $f\left(A_{1}\right) \subseteq A_{2}$ and $f\left(A_{2}\right) \subseteq A_{1}$;

(ii) there exists a constant $\lambda \in\left(0, \frac{1}{2}\right)$ such that

$$
d(f(x), f(y)) \leqslant \lambda\left[d(x, f(x))+d(y, f(y)], \quad \forall(x, y) \in A_{1} \times A_{2} .\right.
$$

Then $\mathrm{f}$ has a unique fixed point that belongs to $A_{1} \cap A_{2}$.

Corollary 4.6. Let $\left\{\mathrm{A}_{i}\right\}_{i=1}^{2}$ be nonempty closed subsets of a complete metric space $(\mathrm{X}, \mathrm{d})$ and $\mathrm{f}: \mathrm{Y} \longrightarrow \mathrm{Y}$ be a given mapping, where $Y=A_{1} \cup A_{2}$. Assume that the following conditions hold

(i) $f\left(A_{1}\right) \subseteq A_{2}$ and $f\left(A_{2}\right) \subseteq A_{1}$;

(ii) there exists a constant $\lambda \in\left(0, \frac{1}{2}\right)$ such that

$$
d(f(x), f(y)) \leqslant \lambda\left[d(x, f(y))+d(y, f(x)], \quad \forall(x, y) \in A_{1} \times A_{2} .\right.
$$

Then $\mathrm{f}$ has a unique fixed point that belongs to $\mathrm{A}_{1} \cap \mathrm{A}_{2}$.

Corollary 4.7. Let $\left\{\mathrm{A}_{i}\right\}_{i=1}^{2}$ be nonempty closed subsets of a complete metric space $(\mathrm{X}, \mathrm{d})$ and $\mathrm{f}: \mathrm{Y} \longrightarrow \mathrm{Y}$ be a given mapping, where $Y=A_{1} \cup A_{2}$. Assume that the following conditions hold

(i) $f\left(A_{1}\right) \subseteq A_{2}$ and $f\left(A_{2}\right) \subseteq A_{1}$;

(ii) there exists a constant $\lambda \in\left(0, \frac{1}{2}\right)$ such that

$$
d(f(x), f(y)) \leqslant \lambda\left(d(x, y)+\frac{d(y, f(y))[1+d(x, f(x))]}{1+d(x, y)}\right), \quad \forall(x, y) \in A_{1} \times A_{2}
$$

Then $\mathrm{f}$ has a unique fixed point that belongs to $A_{1} \cap A_{2}$.

Definition 4.8. Let $(X, \preceq)$ be a partially ordered set and $T: X \rightarrow X$ be a given mapping. We say that $T$ is nondecreasing with respect to $\preceq$ if

$$
x, y \in X, x \preceq y \Longrightarrow T x \preceq T y .
$$

Definition 4.9. Let $(X, \preceq)$ be a partially ordered set. A sequence $\left\{x_{n}\right\} \subset X$ is said to be nondecreasing with respect to $\preceq$ if $x_{n} \preceq x_{n+1}$ for all $n$.

Definition 4.10. Let $(X, \preceq)$ be a partially ordered set and $d$ be a metric on $X$. We say that $(X, \preceq, d)$ is regular if for every nondecreasing sequence $\left\{x_{n}\right\} \subset X$ such that $x_{n} \rightarrow x \in X$ as $n \rightarrow \infty$, there exists a subsequence $\left\{x_{n(k)}\right\}$ of $\left\{x_{n}\right\}$ such that $x_{n(k)} \preceq x$ for all $k$.

We have the following result.

Corollary 4.11. Let $(\mathrm{X}, \preceq)$ be a partially ordered set and $\mathrm{d}$ be a metric on $\mathrm{X}$ such that $(\mathrm{X}, \mathrm{d})$ is complete. Let 
$\mathrm{f}: \mathrm{X} \rightarrow \mathrm{X}$ be a nondecreasing mapping with respect to $\preceq$ and satisfies the following inequality:

$$
\alpha(x, y) d(f(x), f(y)) \leqslant \psi(K(x, y))
$$

for all $x, y \in X$ with $x \succeq y$, where

$$
\begin{gathered}
K(x, y)=\max \left\{d(x, y), \frac{d(x, f(x))+d(y, f(y))}{2}, \frac{d(x, f(y))+d(y, f(x))}{2},\right. \\
\left.\frac{d(x, f(x)) d(y, f(y))}{d(x, y)}, \frac{d(y, f(y))[1+d(x, f(x))]}{[1+d(x, y)]}\right\},
\end{gathered}
$$

and $\psi \in \Psi$. Suppose also that the following conditions hold:

(i) there exists $x_{0} \in X$ such that $x_{0} \preceq f x_{0}$;

(ii) $f$ is continuous or $(X, \preceq, d)$ is regular.

Then $\mathrm{f}$ has a fixed point. Moreover, if for all $\mathrm{x}, \mathrm{y} \in \mathrm{X}$ there exists $z \in \mathrm{X}$ such that $\mathrm{x} \preceq z$ and $\mathrm{y} \preceq z$, we have the uniqueness of the fixed point.

Proof. The proof follows easily from the following: define a mapping $\alpha: X \times X \rightarrow[0, \infty)$ by

$$
\alpha(x, y)= \begin{cases}1, & \text { if } x \preceq y \text { or } x \succeq y, \\ 0, & \text { otherwise. }\end{cases}
$$

We skip the details that can be found in, e.g., $[19,24]$.

Remark 4.12. As a final note, we should mention that the listed corollaries above are not complete. One can observe some more corollaries. For example, one can get the analogs of the listed results above in a partially ordered set by choosing $\alpha(x, y)$ in a proper way like in the corollaries above.

\section{An application}

Example 5.1. Consider the following two-point boundary value problem of second order differential equations:

$$
\left\{\begin{array}{l}
-\frac{\mathrm{d}^{2} x}{\mathrm{dt}^{2}}=f(t, x(t)), t \in[0,1], \\
x(0)=x(1)=0,
\end{array}\right.
$$

where $f:[0,1] \times \mathbb{R} \longrightarrow[0,+\infty[$ is a continuous decreasing function with respect to the second variable and satisfying

(i) for all $t \in[0,1]$ and $x_{1}, x_{2} \in \mathbb{R}$ with $x_{1} \leqslant x_{2}$, we have

$$
\left|f\left(t, x_{1}\right)-f\left(t, x_{2}\right)\right| \leqslant 8 \psi\left(\left|x_{1}-x_{2}\right|\right),
$$

where $\psi \in \Psi$.

Let $C([0,1])$ be the space of all continuous functions defined on $[0,1]$. It is known that this space equipped with the metric $d\left(x_{1}, x_{2}\right)=\left\|x_{1}-x_{2}\right\|_{\infty}=\max _{t \in[0,1]}\left|x_{1}(t)-x_{2}(t)\right|$ is a complete metric space.

We define the Green function associated to (5.1) by

$$
G\left(s_{1}, s_{2}\right)= \begin{cases}s_{1}\left(1-s_{2}\right), & 0 \leqslant s_{1} \leqslant s_{2} \leqslant 1 \\ s_{2}\left(1-s_{1}\right), & 0 \leqslant s_{2} \leqslant s_{1} \leqslant 1\end{cases}
$$

Assume that there exists $x_{0} \in \mathcal{C}([0,1])$ such that for all $t \in[0,1]$, we have 
(ii) $x_{0}(t) \leqslant \int_{0}^{t} G\left(s_{1}, s_{2}\right) f\left(s_{2}, x_{0}\left(s_{2}\right)\right) d s_{2}$.

If (i) and (ii) are satisfied, then the problem (5.1) has a unique solution $x^{\star} \in C^{2}([0,1])$.

Proof. It is easy to see that $x^{\star} \in \mathrm{C}([0,1])$ is a unique solution of (5.1) if and only if $x^{\star}$ is the unique fixed point of the mapping $\mathrm{T}: \mathrm{C}([0,1] \longrightarrow \mathrm{C}([0,1]$ defined by

$$
\mathrm{Tx}(\mathrm{t})=\int_{0}^{1} \mathrm{G}\left(\mathrm{s}_{1}, \mathrm{~s}_{2}\right) \mathrm{f}\left(\mathrm{s}_{2}, x\left(\mathrm{~s}_{2}\right)\right) \mathrm{d} \mathrm{s}_{2}, \quad \forall \mathrm{t} \in[0,1] .
$$

If we define the function $\alpha: C([0,1]) \times C([0,1]) \longrightarrow[0,+\infty[$ by

$$
\alpha(x, y)= \begin{cases}1, & \text { if } y(t) \geqslant x(t), \\ 0, & \text { otherwise }\end{cases}
$$

thus, $\mathrm{T}$ is $\alpha-\psi-\mathrm{K}^{\star}$-mapping since for all $\mathrm{x}_{1}, \mathrm{x}_{2} \in \mathrm{C}([0,1])$, we have $\alpha\left(\mathrm{x}_{1}, \mathrm{x}_{2}\right)\left\|\mathrm{T}\left(\mathrm{x}_{1}\right)-\mathrm{T}\left(\mathrm{x}_{2}\right)\right\|_{\infty} \leqslant \psi\left(\| \mathrm{x}_{1}-\right.$ $\left.x_{2} \|_{\infty}\right) \leqslant \psi\left(K^{\star}\left(x_{1}, x_{2}\right)\right)$ (see Theorem 4.1 in [24]). Moreover, the condition $(\mathrm{H})$ is satisfied by taking $z=$ $\min \{x, y\}, x, y \in C([0,1]$. By applying Theorem 2.9, we get the desired result.

\section{Acknowledgement}

The authors express their gratitude to the referees for constructive and useful remarks and suggestions.

\section{References}

[1] R. P. Agarwal, M. A. Alghamdi, N. Shahzad, Fixed point theory for cyclic generalized contractions in partial metric spaces, Fixed Point Theory Appl., 2012 (2012), 11 pages. 4

[2] M. U. Ali, T. Kamran, E. Karapınar, A new approach to $(\alpha, \psi)$-contractive nonself multivalued mappings, J. Inequal. Appl., 2014 (2014), 9 pages. 1

[3] M. U. Ali, T. Kamran, E. Karapınar, Fixed point of $\alpha-\psi$-contractive type mappings in uniform spaces, Fixed Point Theory Appl., 2014 (2014), 12 pages. 1

[4] S. Banach, Sur les opérations dans les ensembles abstraits et leur application aux équations intégrales, Fund. Math., 3 (1922), 133-181. 3.2

[5] V. Berinde, Contracţii generalizate şi aplicaţii, (Romanian) [[Generalized contractions and applications]] Colecia Universitaria (Baia Mare) [University Collection], Editura Cub Press, Baia Mare, (1997). 1, 1.1

[6] V. Berinde, Iterative approximation of fixed points, Editura Efemeride, Baia Mare, (2002). 3.3

[7] M. Berzig, E. Karapınar, Note on "Modified $\alpha$ - $\psi$-contractive mappings with applications, Thai J. Math., 13 (2015), 147-152. 1

[8] S. K. Chatterjea, Fixed-point theorems, C. R. Acad. Bulgare Sci., 25 (1972), 727-730. 3.12

[9] C.-M. Chen, E. Karapinar, Fixed point results for the $\alpha$-Meir-Keeler contraction on partial Hausdorff metric spaces, J. Inequal. Appl., 2013 (2013), 8 pages. 1

[10] B. K. Dass, S. Gupta, An extension of Banach contraction principle through rational expression, Indian J. Pure Appl. Math., 6 (1975), 1455-1458. 3.13

[11] A. N. Gupta, A. Saxena, A unique fixed point theorem in metric spaces, Math. Student, 52 (1984), 156-158. 3.5

[12] G. E. Hardy, T. D. Rogers, A generalization of a fixed point theorem of Reich, Canad. Math. Bull., 16 (1973), $201-206$. 3.10

[13] N. Hussain, Z. Kadelburg, S. Radenović, F. Al-Solamy, Comparison functions and fixed point results in partial metric spaces, Abstr. Appl. Anal., 2012 (2012), 15 pages. 1

[14] D. S. Jaggi, Some unique fixed point theorems, Indian J. Pure Appl. Math., 8 (1977), 223-230. 3.4

[15] R. Kannan, Some results on fixed points, Bull. Calcutta. Math. Soc., 60 (1968), 71-76. 3.11

[16] E. Karapinar, Fixed point theory for cyclic weak $\phi$-contraction, Appl. Math. Lett., 24 (2011), 822-825. 4

[17] E. Karapinar, I. M. Erhan, Cyclic contractions and fixed point theorems, Filomat, 26 (2012), 777-782.

[18] E. Karapınar, İ. M. Erhan, A. Y. Ulus, Fixed point theorem for cyclic maps on partial metric spaces, Appl. Math. Inf. Sci., 6 (2012), 239-244. 4

[19] E. Karapinar, B. Samet, Generalized $\alpha-\psi$ contractive type mappings and related fixed point theorems with applications, Abstr. Appl. Anal., 2012 (2012), 17 pages. 1, 3.8, 3.9, 4, 4.2, 4 
[20] W. A. Kirk, P. S. Srinivasan, P. Veeramani, Fixed points for mappings satisfying cyclical contractive conditions, Fixed Point Theory, 4 (2003), 79-89. 4, 4.4

[21] M. Păcurar, I. A. Rus, Fixed point theory for cyclic ф-contractions, Nonlinear Anal., 72 (2010), 1181-1187. 4.3

[22] I. A. Rus, Generalized contractions and applications, Cluj University Press, Cluj-Napoca, (2001). 1, 1.1

[23] I. A. Rus, Cyclic representations and fixed points, Ann. T. Popoviciu Seminar Funct. Eq. Approx. Convexity, 3 (2005), 171-178. 4

[24] B. Samet, C. Vetro, P. Vetro, Fixed point theorems for $\alpha \psi$-contractive type mappings, Nonlinear Anal., 75 (2012), 2154-2165. 1, 1, 1, 4, 5 